\title{
Research on Application-Oriented Teaching Reform of Urban Design Course
}

\author{
Mingchun $\mathrm{Ma}^{1, *}$, Xiao Wang ${ }^{1}$ and Qiang $\mathrm{Liu}^{1}$ \\ ${ }^{1}$ School of Civil Engineering and Architecture, University of Jinan, Jinan, China \\ *Corresponding author. Email:mamingchun@163.com
}

\begin{abstract}
Based on the change of urban construction background from "incremental planning" to "stock planning" and the change of urban construction content from spatial expansion to urban renewal, this paper studies the knowledge system, practical means, teaching content and teaching mode of urban design curriculum, and integrate the methods of multidisciplinary support, embedding of urban investigation and learning community model, etc. into teaching process and explores the application-oriented urban design curriculum reform. The paper analyzes the contradictions between the urban design teaching and current industry development, such as traditional single vision of the thinking mode and the complex present condition, the traditional emphasis on space design theory knowledge structure and the demands of multiple stakeholders theory, the conflict between traditional emphasis on space design of knowledge structure and the demands of multiple stakeholders, etc. In view of these problems, this paper proposes solutions to integrate methods such as multidisciplinary support, embedding of urban investigation and learning community model into the teaching process, and explores application-oriented urban design curriculum reform.
\end{abstract}

Keywords: stock planning, urban design teaching, learning community, new engineering specialties

\section{INTRODUCTION}

With the acceleration of urbanization, livability, green, ecology and inclusiveness have become the trend of urban development in the whole world. The theme of the annual meeting of China's urban planning held on December 24, 2018 is defined as "sharing and quality". The content and characteristics of urban construction have changed [1]. "Urban Design" is the core course of urban and rural planning and architecture major, including urban design theory for junior students and urban design practice for senior students. Facing the change of industry background from traditional "incremental planning" to "stock planning" and the change of urban construction content from spatial expansion to urban renewal, the original teaching knowledge system, practical means, teaching content and teaching mode of urban design course need to be reformed to meet the needs of the industry.

\section{ANALYSIS ON THE BACKGROUND CHANGE OF URBAN DESIGN INDUSTRY}

\subsection{The main content of urban construction has changed from spatial expansion to connotation enhancement}

After the stage of rapid urbanization, China's urban development mode has gradually changed-from the "piespreading" type of extension incremental expansion to the connotative stock optimization stage. The efficient utilization of existing space has become an important way to promote the transformation and development of the city, optimize the functional structure of the city, and improve the quality and connotation of the space environment. In this case, the traditional incremental urban design based on spatial expansion began to turn to the stock urban design based on quality upgrading, that is, urban renewal.

In 2007, Shenzhen's new round of master planning became the first master planning from increment to stock in the country, and the trend of urban stock planning began to be clear. In 2011, China's urbanization level exceeded 50\%, and the proportion of increment and stock changed significantly, and urban planning has entered stock planning. In 2013, a new round of master plan for Shanghai began to be approved, which clearly defined the requirement of zero land growth. Since then, stock planning has become an important topic in the urban planning industry [2]. In 2014, the six major goals put 
forward by the National Urbanization Conference were all about stock planning. In March 2017, the Ministry of Housing and Urban-Rural Development issued the Guiding Opinions on Strengthening Ecological Restoration and Urban Repair Work, which arranged to deploy the main work contents of urban renewal nationwide-ecological restoration and urban repair work. The theme of the annual meeting of urban planning held on November 24, 2018 directly proposes that the direction of urban planning will change from "due to demand" to "quality planning".

It can be seen from this that both urban construction projects and national policies reflect that urban renewal has become the main content of current urban design, and the research objects and working methods of urban design will change.

\subsection{Higher professional requirements for urban design}

In March 2011, the Academic Degrees Committee of the State Council and the Ministry of Education proposed to separate urban and rural planning and landscape architecture from the original first-class discipline of architecture and establish them as first-class disciplines. Urban design was also promoted to one of the six subdiscipline programs on architecture. However, in February 2016, "Several Suggestions of the CPC Central Committee and the State Council on Further Strengthening the Management of Urban Planning and Construction" proposed "improving the level of urban design" and "supporting institutions of higher learning to set up major related to urban design and establish and cultivate urban design teams". In 2017, the Ministry of Housing and Urban-Rural Development successively released the list of cities for the first and second batches of urban design pilot projects, implementing the pilot work from four aspects: innovating management systems, exploring technical methods, inheriting history and culture, and improving the quality of cities. It can be seen that the position of urban design in urban construction is rapidly improving, and the professional requirements for urban design are also constantly improving.

\section{ANALYSIS OF CONTRADICTIONS IN TEACHING CURRENT SITUATION OF URBAN DESIGN COURSE}

\subsection{Contradiction between the traditional single vision mode of thinking and the complex status}

Under the incremental urban construction, the main work content of traditional urban design is to build new urban material space, which is a single vision thinking mode. It emphasizes the morphological results of urban design, pays attention to the visual quality and aesthetic experience of urban space, and places culture, society, economy, politics and the formation of spatial elements in a secondary position. However, the fundamental goal of urban design under the background of stock is to properly intervene in the space environment on the basis of understanding the internal laws of urban space, to solve the contradiction between the current needs and the space environment, to meet people's demands on the material, use and emotion of the space environment, and to shape a space environment for sustained and healthy development. However, over the years, a large number of complicated situations such as the city's functions under the standard construction, the demands of different residents, and the balance of different interest groups are not problems that can be solved by a single vision planning thinking. [3]

Therefore, in the teaching of urban design in colleges and universities, the teaching concept should be adjusted to train students to examine the complex problems of stock space from multiple perspectives and to cultivate students' critical thinking ability on complex problems.

\subsection{Contradiction between the traditional theoretical knowledge structure focusing on space design and the demands of multiple interest subjects}

The knowledge structure of traditional urban design theory is more inclined to the design of material space form; emphasize the application of visual aesthetics in urban space design. The focus of the course is on visual quality and aesthetic experience. However, just as modern rationalism excessively pursues urban functions, if it excessively pursues the visual aesthetic problems of urban space and ignores the social and cultural factors behind space, the final result will only be the proliferation of formalism.

Under the mode of incremental city construction, the main work content of traditional urban design is to build a new urban public space, which is single vision thinking. In the setting of theoretical curriculum system, more attention is paid to the formal design of urban space, brand-new functional layout and complete road network system. For students, the content of classroom teaching is more inclined to purely express the blueprint of designer's thoughts [4]. After the change of industry background, the focus of stock planning has been changed to the reset of urban functions and the reconstruction of multi-interest pattern. This requires urban design to balance the needs of government, developers, indigenous inhabitants and other multi-interest subjects from sociology, economics, policy research and other aspects on the basis of urban space. In this case, the knowledge structure of curriculum teaching obviously lags behind the needs of industry application, resulting in students' design schemes often too idealistic to solve practical problems. 


\subsection{Contradictions between traditional urban design techniques and the construction of new engineering specialties}

At present, the main content of urban design teaching is material space planning with industry skills education as the leading factor and training urban and rural planners and architects as the goal. It is no longer suitable for the highquality compound talents training goal with strong practical ability and innovative ability, which has been put forward by the state since 2017 with the Internet and industrial intelligence as the core.

However, with the help of more scientific network technology support, data analysis and spatial simulation, relevant investigation and evaluation factor analysis will be carried out on the current use of public space, the operation of commercial service facilities, the influencing factors of infrastructure such as transportation, etc., which will make the design results more reasonable and feasible.(Fig. 1)
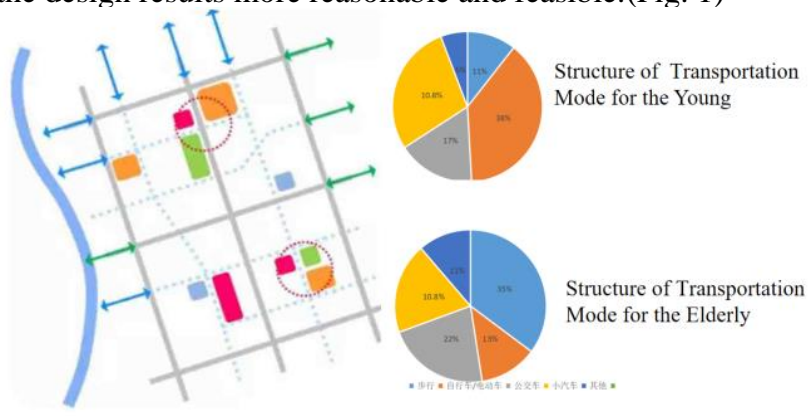

Figure 1. Data Analysis

\subsection{Contradiction between the traditional theoretical knowledge structure focusing on space design and the demands of multiple interest subjects}

The theoretical basis of the traditional teaching mode is behaviorism learning theory, which emphasizes learners' passive response to external stimuli. The teaching mode produced under this educational concept is a teaching mode of "transmission, help and guidance" with teachers as the main body and teachers taking disciples. In classroom teaching, the teacher modifies the plan for the students, and the students adjust it according to the teacher's modification opinions. In this state, the students are in passive learning and lack learning initiative.

At present, the goal of talent training in colleges and universities is to cultivate innovative talents, which requires students to be the main body and give full play to their subjective initiative. Therefore, it is urgent to establish a new teaching organization mode to meet the needs of talent development. [4]

However, as the core course of undergraduate teaching for urban and rural planning and architecture major, how to break through the traditional teaching content and teaching mode and realize the docking between major and new social needs under the background of urban renewal is the key issue that our research group has been exploring and practicing in recent years.

\section{RESEARCH ON TEACHING REFORM OF URBAN DESIGN COURSE}

\subsection{Adjust the syllabus with multi-discipline as the support}

The interest subjects involved in urban design include many aspects, including the government, economic organizations and the public. Each party has its own interest demands. Urban space allocation is the result of various interest games. Urban designers play an important role in it, taking public interests as the leading factor, to meet the multi-interest demands of the government, developers and the public, and to realize win-win results in economic benefits, environmental benefits and social benefits of urban construction.(Table 1)

The urban design course is aimed at senior undergraduates majoring in architecture and urban and rural planning. Students already have certain professional abilities, In order to adapt to the complex situation in urban renewal, the teaching syllabus of urban design theory has adjusted the original teaching content and added the contents of other disciplines and planning technology: sociology and economics have been added to the part of urban space theory; The original part of urban design elements was adjusted to 2-hour social investigation and 2-hour design element analysis. GIS spatial evaluation analysis is added to the original urban design methods and case introduction at all levels. In addition, the content of urban design technology can be increased in many links such as site investigation, spatial cognition and visual landscape investigation.

Table 1. Technical Methods of Urban Design Investigation

\begin{tabular}{|c|c|c|c|}
\hline $\begin{array}{c}\text { Technical } \\
\text { Category }\end{array}$ & $\begin{array}{c}\text { Technical } \\
\text { Name }\end{array}$ & $\begin{array}{c}\text { Research } \\
\text { Content }\end{array}$ & $\begin{array}{c}\text { Technical } \\
\text { Tools }\end{array}$ \\
\hline \multirow{2}{*}{$\begin{array}{c}\text { Site Use } \\
\text { Survey }\end{array}$} & $\begin{array}{c}\text { Questionnaire } \\
\text { Survey }\end{array}$ & $\begin{array}{c}\text { Use } \\
\text { Satisfaction } \\
\text { Survey }\end{array}$ & WEB \\
\cline { 2 - 3 } & SPSS \\
\hline Spatial & $\begin{array}{c}\text { Baidu Heat } \\
\text { Map }\end{array}$ & $\begin{array}{c}\text { The number of } \\
\text { people in } \\
\text { different } \\
\text { periods }\end{array}$ & WEB \\
\cline { 2 - 4 } Imagery & $\begin{array}{c}\text { Spatial } \\
\text { Perception } \\
\text { Investigation }\end{array}$ & $\begin{array}{c}\text { Large-scale } \\
\text { investigation, } \\
\text { analysis of } \\
\text { space } \\
\text { openness }\end{array}$ & GIS \\
\hline
\end{tabular}




\subsection{Embedding of Urban Investigation and Analysis of Science and Technology}

In the theoretical part of urban design, urban research is added, students are taken to give situational lectures in urban space, and the spatial elements of urban design are explained in specific scenes, which is helpful for better understanding. At the same time, a variety of research technologies are used in urban research. In addition, I have the most intuitive feeling about the contradiction of diversified interest subjects in urban renewal. This grassroots experience of entering the city will guide students to consider the demands of various interests in the urban design practice of the senior year.

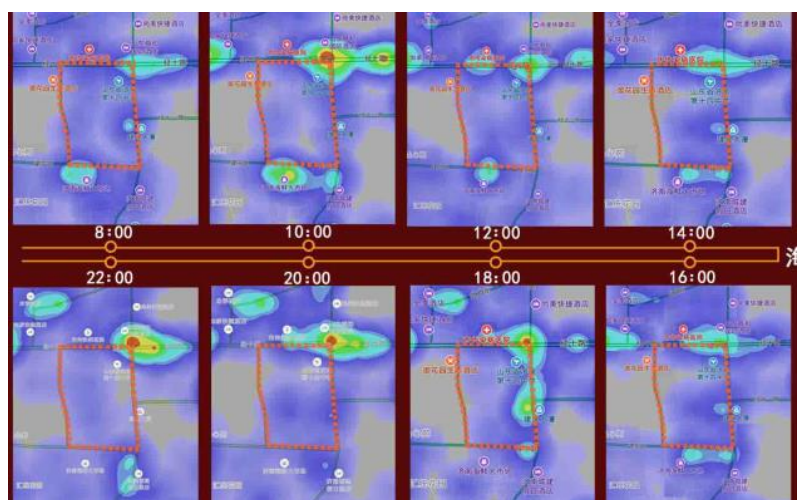

Figure 2. Analyzes the Number of Crowds in Different Periods Using Baidu Thermal Diagram

\section{3. "Learning Community" through the whole process of urban design practice course}

According to the teaching organization of the "learning community" in recent years, it is very helpful to the professional promotion of students. The mutual promotion effect between the students in the group is far greater than the supervision of the teachers, and the ability of students to cooperate with others is cultivated. However, this kind of organization method is often limited to the investigation at the beginning of the design, and still returns to the traditional teaching method in the later curriculum design.

This project will explore the method of "learning community" throughout the whole process of urban design practice course, from initial investigation and analysis to scheme design, and then to final report and evaluation. At the beginning of the research, the teacher gave a large area, and the "learning community" agreed on its own research objects and topics to give full play to the interests of students. In the scheme design stage, the "learning community" discusses the scheme from various angles, conducts rich exchanges and speculation, and enables students to fully display themselves. In the reporting and evaluation stage, the "learning community" is taken as a unit to report the plan to all the students and accept the replies of all the students and teachers, so as to enhance the students' comprehensive expression ability and professional identity [5].
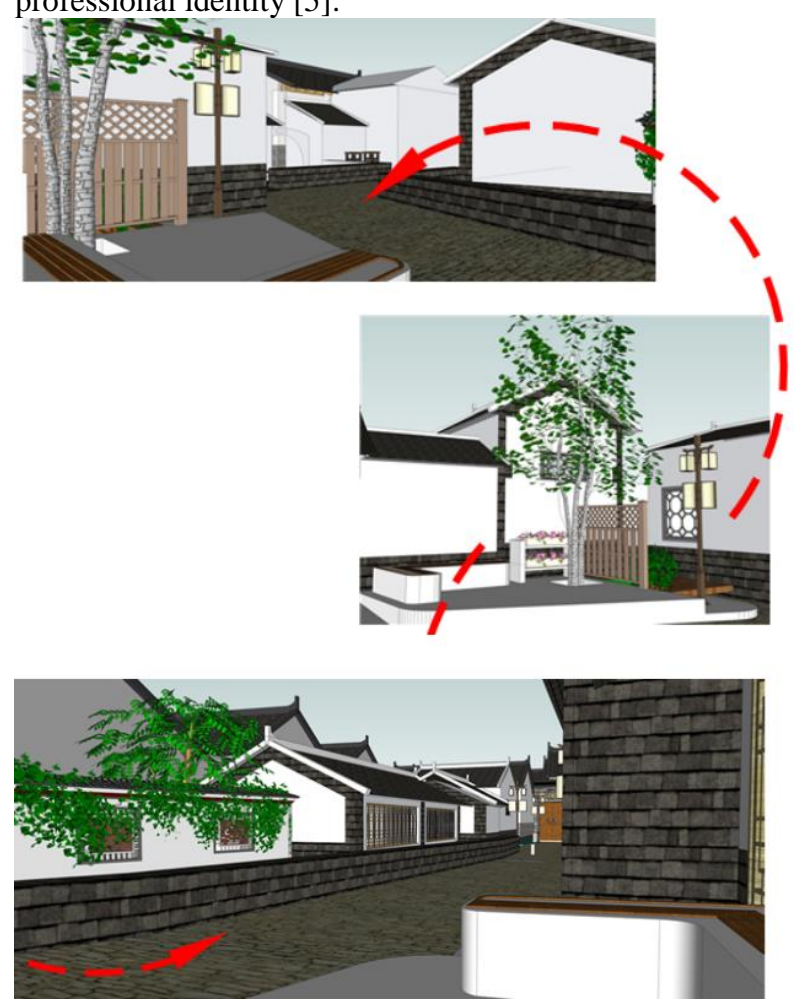

Figure 3. Various Types of Research Results

Using the teaching form organized by the learning community, we not only pay attention to the cultivation of design ability but also pay more attention to the cultivation of research thinking ability, changing the "teaching style" to the "discussion style" and the "one-word hall" to the "group-word hall". This teaching method meets the psychological needs of college students to actively acquire knowledge and improve their professional ability and is conducive to the cultivation of innovative talents.

\section{CONCLUSION}

In the process of urbanization, incremental planning is gradually decreasing, and the era of stock planning dominated by urban renewal has come [6]. This change in industry background has new requirements for urban design professionals, and university education courses have to be adjusted accordingly. In the teaching process, multidisciplinary cross-cutting, the introduction of urban research, learning community organization, etc. are taken as the entry points to carry out teaching reform research on urban design theory and design curriculum, and form an urban curriculum system suitable for the new industry background. 


\section{ACKNOWLEDGMENTS}

This work was financially supported by the Project of Ministry of Education Industry University Research Collaborative Education (t201802252003), the Key Teaching and Research e Foundation of University of Jinan (JZ1806).

\section{REFERENCES}

[1] Liu Zheng. Research on the Planning and Promotion Strategy of Creative Industry Zone for Industrial Heritage Transformation in the Context of Stock Planning-Taking the Overall Planning and Design of Beijing 751 Creative Industry Zone as an Example [J]. Urban Architecture 2017 (4).

[2] Li Hao. Significance of Public Space-Value Speculation and Reconstruction of Public Space in
Contemporary China (M). Beijing: China Construction Industry Press, 2016.

[3] Zhao Liang, Wu Yue, Liu Chenyang, Zhao Bin. Research on the Framework of Urban Design Training System under Interdisciplinary Integration. Urban Planning 2019(5).

[4] Xi Zhang, Yu Haiyan. Analysis on the Reform of Talent Training Mode in Newly-built Undergraduate Colleges during the Transition Period [J]. Higher Education Research 2016(09)

[5] Gao Wen.Constructivist Educational Research (M). Beijing: Educational Science Press, 2015

[6] Liu Wei, Lv Tao. Urban Renewal in the Context of Stock-Reflections on the Direction of Planning Transformation [J]. Shanghai Urban Planning 2017(10). 